See Article page 1359.

\section{Commentary: Alternative access leads the willing and drags along the reluctant}

\author{
Moritz C. Wyler von Ballmoos, MD, and \\ Michael J. Reardon, MD
}

Over the past decade and in a series of trials, transcatheter aortic valve replacement (TAVR) has established itself as an acceptable and less invasive form of aortic valve replacement (AVR) in all surgical risk categories. ${ }^{1}$ In these trials, surgical AVR (SAVR) was compared with the ever-evolving and improved TAVR systems of either the balloon-expandable or self-expanding type. Many of the early improvements were directed at reducing the profile of the delivery systems. Initially, the delivery systems of transcatheter heart valves were specifically designed for transapical (TA) access, although the very first case of TAVR in humans was performed in an antegrade fashion via interatrial septum puncture and the left ventricle. ${ }^{2}$ The downside of TA access was quickly recognized, and various groups worked feverishly on reducing the delivery system profile to make a transfemoral (TF) approach feasible in more patients. Although early generations of transcatheter heart valve required delivery systems of $24 \mathrm{Fr}$, contemporary systems have been reduced to 14 and $16 \mathrm{Fr}$, corresponding to diameters of 4.45 and $5.1 \mathrm{~mm}$, respectively.

In this edition of the Journal, Junquera and colleagues ${ }^{3}$ present an elegant review of the literature on the evolution of TAVR access and compare TF, the currently most ubiquitous access route, with other alternative access options. TF access has not become the preferred TAVR access route by chance; it is a familiar access strategy for surgeons and interventionalists, especially when large-bore access is required. Endovascular aneurysm repairs have been

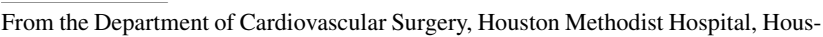
ton, Tex.

Disclosures: The authors reported no conflicts of interest.

The Journal policy requires editors and reviewers to disclose conflicts of interest and to decline handling or reviewing manuscripts for which they may have a conflict of interest. The editors and reviewers of this article have no conflicts of interest.

Received for publication April 24, 2021; revisions received April 24, 2021; accepted for publication April 26, 2021; available ahead of print May 3, 2021.

Address for reprints: Michael J. Reardon, MD, Department of Cardiovascular Surgery, Houston Methodist Hospital, 6550 Fannin, Suite 1401, Houston, TX 77030 (E-mail: mreardon@ houstonmethodist.org).

J Thorac Cardiovasc Surg 2023;165:1371-2

$0022-5223 / \$ 36.00$

Copyright (c) 2021 by The American Association for Thoracic Surgery

https://doi.org/10.1016/j.jtcvs.2021.04.078
}

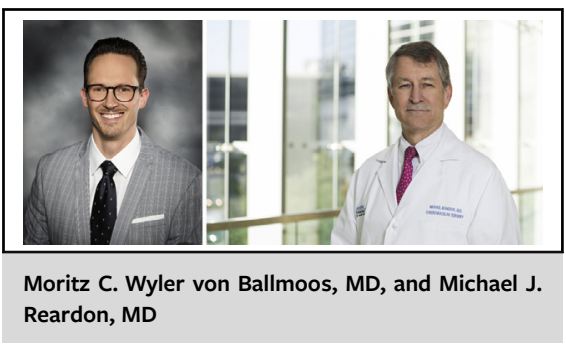

CENTRAL MESSAGE

Alternative access without chest wall penetration provides a reasonable substitute for transfemoral access TAVR.

performed through this access predating TAVR. ${ }^{4}$ It is by far the most favorable access route from an ergonomic and radiation safety standpoint. ${ }^{5}$

As the authors report, the number of patients requiring alternative, non-TF access has decreased dramatically with lower-profile delivery systems. Alternative access was permitted in all landmark TAVR trials but one, the PARTNER 3 trial. Subsequently, investigators have compared TF and alternative access and often found alternative access to be associated with generally worse outcomes. $^{6,7}$ This has stimulated further investigation of the topic in registries and other pooled observational data. Many of these studies have suggested an increased risk with alternative access, but these studies are burdened by substantial methodological limitations. ${ }^{8}$ Patients who have no suitable femoral access are, by definition, sicker patients; they either are lower extremity amputees or severe vasculopaths, dragging implanters along an alternative access route. Hence, the associated risk in these patients is not so much derived from them undergoing TAVR by alternative access route per se, but rather from the fact that they need an alternative access route. This is an important differentiation to keep in mind.

Adjuncts for vascular access, such as intravascular lithotripsy, may facilitate TF access in otherwise unsuitable candidates, but almost certainly will not have the lower risk profile associated with TF access in general. Similarly, alternative access might well be a safer option in patients with questionable lower extremity arterial anatomy. Arguably, alternative access should then lead the willing, and perhaps more often. The one notable exception to this is TA access, which is a substantially more invasive route overall. Another important consideration, especially with 
regard to stroke risk, is the extent of atherosclerosis and calcification of the aortic arch vessels when choosing an alternative access strategy via the axillary, carotid, or innominate artery. We commend the authors on a very nice review of the topic, which continues to be of great interest and importance to the field.

\section{References}

1. Wyler von Ballmoos MC, Reardon MJ. Who should get surgical aortic valve replacement in the era of transcatheter aortic valve replacement? A surgeon's perspective. Ann Cardiothorac Surg. 2020;9:487-9.

2. Cribier A, Eltchaninoff H, Bash A, Borenstein N, Tron C, Bauer F, et al. Percutaneous transcatheter implantation of an aortic valve prosthesis for calcific aortic stenosis: first human case description. Circulation. 2002;106:3006-8.
3. Junquera L, Kalavrouziotis D, Dumont E, Rodés-Cabau J, Mohammadi S. Paradigm shifts in alternative access for transcatheter aortic valve replacement: an update. J Thorac Cardiovasc Surg. 2023;165:1359-70.e2.

4. Ivancev K, Vogelzang R. A 35 year history of stent grafting, and how EVAR conquered the world. Eur J Vasc Endovasc Surg. 2020;59:685-94.

5. Aquino A, Khiabani AJ, Henn MC, Zajarias A, Melby SJ, Sintek M, et al. Radiation exposure during transcatheter valve replacement: what cardiac surgeons need to know. Ann Thorac Surg. 2020;109:118-22.

6. Leon MB, Smith CR, Mack MJ, Makkar RR, Svensson LG, Kodali SK, et al. Transcatheter or surgical aortic-valve replacement in intermediate-risk patients. N Engl J Med. 2016;374:1609-20.

7. Reardon MJ, Van Mieghem NM, Popma JJ, Kleiman NS, Søndergaard L, Mumtaz M, et al. Surgical or transcatheter aortic-valve replacement in intermediate-risk patients. N Engl J Med. 2017;376:1321-31.

8. O'Hair DP, Bajwa TK, Popma JJ, Watson DR, Yakubov SJ, Adams DH, et al. Direct aortic access for transcatheter aortic valve replacement using a selfexpanding device. Ann Thorac Surg. 2018;105:484-90.

\section{Commentary: An all-access pass to transcatheter aortic valve replacement}

\section{Hellmuth R. Muller Moran, MD, Aaron J. Spooner, MD, MEHP, MMgt, FRCSC, and Michael H. Yamashita, MDCM, MPH, FRCSC}

From the first-in-man description by Cribier and colleagues in $2002^{1}$ to the most recently published guidelines on valvular heart disease in $2020,{ }^{2}$ transcatheter aortic valve replacement (TAVR) has evolved from a niche procedure to a standard intervention. This has revolutionized the treatment of aortic stenosis, but also produced several unanswered questions with regard to valve durability, subclinical leaflet thrombosis, permanent pacemaker insertion with subsequent rehospitalization, the evolving role of TAVR in low-risk patients, and preparing future cardiac surgeons for practices that include transcatheter techniques. ${ }^{3-5}$

\footnotetext{
From the Division of Cardiac Surgery, Department of Surgery, Max Rady College of Medicine, University of Manitoba, Winnipeg, Manitoba, Canada; and Cardiac Sciences Program, St Boniface Hospital, Winnipeg, Manitoba, Canada.

Disclosures: The authors reported no conflicts of interest.

The Journal policy requires editors and reviewers to disclose conflicts of interest and to decline handling or reviewing manuscripts for which they may have a conflict of interest. The editors and reviewers of this article have no conflicts of interest.

Received for publication May 3, 2021; revisions received May 3, 2021; accepted for publication May 4, 2021; available ahead of print May 7, 2021.

Address for reprints: Michael H. Yamashita, MDCM, MPH, FRCSC, Cardiac Sciences Program, St Boniface Hospital, Y3519-409 Tache Ave, Winnipeg, Manitoba, R2H 2A6 Canada (E-mail: myamashita@sbgh.mb.ca).

J Thorac Cardiovasc Surg 2023;165:1372-3

$0022-5223 / \$ 36.00$

Copyright (c) 2021 by The American Association for Thoracic Surgery

https://doi.org/10.1016/j.jtcvs.2021.05.006
}

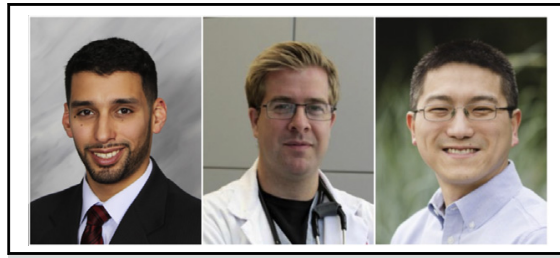

Hellmuth R. Muller Moran, MD, Aaron J. Spooner, MD, MEHP, MMgt, FRCSC, and Michael H. Yamashita, MDCM, MPH, FRCSC

\section{CENTRAL MESSAGE}

Many alternatives to transfemoral TAVR are available. Patient, operator, and institutional factors should be considered when

Naturally, deciding the optimal access

although route.

transfemoral

TAVR (TF-

TAVR) is the

preferred route, questions surrounding the ideal alternative access have persisted for those patients not suitable for TF-TAVR.

Junquera and colleagues ${ }^{6}$ concisely and thoroughly review options for alternative access during TAVR. When available, they provide evidence comparing outcomes after each approach with TF-TAVR and with each other. The number of non-TF-TAVRs performed is not insignificant. Based on the most recent report of the Transcatheter Valve Therapy (TVT) Registry, nearly 3500 individuals underwent non-TF-TAVR in 2019 in the United States alone ( $\sim 5 \%$ of TAVRs performed), whereas almost 27,500 